American Journal of Pharmacology and Toxicology 2 (2): 75-79, 2007

ISSN 1557-4962

(C) 2007 Science Publications

\title{
Sensitization of Photohemolysis by a New Extraction from Flowers and Aerial Parts of Cichorium Pumilum Jacq: Effects of Inulin and Hydrogen Peroxide
}

\author{
${ }^{1}$ M-Ali H. Al-Akhras, ${ }^{2}$ Amr Amin, ${ }^{2}$ Karima Mohammad, ${ }^{2}$ Fedae AlHaddad, ${ }^{2}$ Alaaeldin Hamza \\ ${ }^{1}$ Department of Physics UAE University, \\ ${ }^{2}$ Department of Biology UAE University
}

\begin{abstract}
Addition of inulin and hydrogen peroxide to new photosensitizers extracted from the flowers and aerial parts of the chicory (Cichorium Pumilum Jacq) have been investigated. Some of the isolated photosensitizers remain unidentified compounds. Chicory extracts are found to be dependent on light and temperature. Higher photohemolysis rate was noticed under the influence of light as compared to temperature. The effect of $\mathrm{H}_{2} \mathrm{O}_{2}$ on phototoxicity reported in this study showed a rapid reduction in the fractional hemolysis percentage at higher temperature. Compared to erythrocytes with higher concentrations and under the influence of solar irradiance $505.29 \pm 24.96 \mathrm{w} / \mathrm{m}^{2}$, erythrocytes with lower concentrations of inulin and $\mathrm{H}_{2} \mathrm{O}_{2}$ were ruptured faster. Samples with $0.95 \mathrm{mg} / \mathrm{ml}$ of herb extract and different concentrations of inulin $(1 \mathrm{mg} / \mathrm{ml}-2 \mathrm{mg} / \mathrm{ml})$ shows no temperature effects at $40^{\circ} \mathrm{C}$ in the absent of sunlight.
\end{abstract}

Key words: Cichorium Pumilum, photobiology, photohemolysis, chicory, photosensitizer, Inulin and Hydrogen Peroxide

\section{INTRODUCTION}

Cichorium Pumilum Jacq (chicory) from Asteraceae family grows naturally in the local areas with no needs for irrigation or chemical fertilizers. Chicory is a plant known to cause quick death of white sheep especially during its flowering period in autumn. Same species of chicory, cultivated in gardens, are called Cichorium intybus L. Chicory is one of the main herbs used in Middle East. Multiple uses of different plant parts have been reported. Roasted roots that are rich in inulin have been used as a coffee substitute for centuries, root extracts have also been used as a remedy for malaria ${ }^{[1]}$, antibacterial activity ${ }^{[2]}$, and cancer of the breast and face ${ }^{[3,4]}$, and against Ehrlich ascites carcinoma $^{[5]}$. Leaves are very common in salad as they promote appetite, digestion ${ }^{[6]}$, and possess strong antioxidant properties ${ }^{[2]}$. Their juice is known in folk medicine as a remedy to treat uterus tumors along with many other tumor types. Chicory seeds are used for treating liver diseases ${ }^{7]}$. Aerial parts are used to relief stomach pains ${ }^{[8]}$. Chicory's flowers are source of cichoriin which is known to be sensitive to light ${ }^{[9]}$. Similarly, lactucin, extracted from chicory roots, is found to be sensitive to light ${ }^{[1,10]}$. In addition, chicory has been shown to reduce intensity of internal parasites in grazing sheep ${ }^{[11-13]}$. Chicory's effects on the viability of gastrointestinal nematodes and lungworm larvae in vitro were found to be minimal on hatching and development of nematode eggs and larvae. Chicory did, however, reduce the number of lungworm larvae developing to the L3 stage ${ }^{[14]}$. Furthermore, in chicory root explants, light has been shown to induce a significant increase of chlorophyll content, lignin content, level of apoplastic proteins and anodic isoforms. Light has also been reported to inhibit the peroxidase isoenzymes involved in indoleacetic acid degradation and to stimulate those involved in lignification ${ }^{[15]}$.

Inulin is a polymer of fructose found to be one of the main compounds presents in chicory roots ${ }^{[16]} \cdot \mathrm{H}_{2} \mathrm{O}_{2}$ is a powerful oxidizing agent that is produced in our blood and act as the first line of defense against toxins, parasites, bacteria, viruses and yeast. The present report investigates photosensitizers extracted from the flowers and aerial parts of the chicory plants ${ }^{[17]}$. Cichoriin extracted from chicory flowers and Lactucin extracted from chicory roots are some of the expected extracted ingredients that are sensitive to light. Thus, the main goals of the present study are to utilize herbal plants as potential source of photosensitizer, to elucidate their phototoxicity and their potential in photodynamic therapy (PDT). Finally, some of the present results were fitted to Gompertz function module ${ }^{[7-19]}$. The Gompertz function is defined as:

$$
H=H_{0} e^{-a e^{-b t}}
$$

where: $\boldsymbol{H}$ is the percentage of hemolysis during the lysis time $\boldsymbol{t}$ (the time measured from start of rupturing the RBCs at dark incubation). $\boldsymbol{H}_{0}$ is the initial maximum number of cells, normalized to one, $\boldsymbol{a}$ is a fractional hemolysis ratio, and $\boldsymbol{b}$ is the rate of fractional hemolysis change.

\section{MATERIALS AND METHODS}

Plant extraction: Flowers and aerial parts of chicory were collected from local wild areas in northern Jordan during end of May 2006. Collected plant parts were washed with running water and were then air dried in a dark room. Chicory flowers and aerial parts were extracted using a microwave-assisted extraction method

Corresponding Author: M-Ali Al-Akhras, Permanent address: Department of Physics, Jordan University of Science and Technology, P. O. Box 3030 Irbid-Jordan 
as described in ${ }^{[17,20]}$. In this method, extraction is based on the selective heating of the matrix that contains the target extract when the matrix is immersed in a solvent such as ethanol and water, which is transparent to the microwaves. This solvent, allows for selective heating of particular components within the materials being treated, without using excessive energy. The dried flower and aerial parts of chicory were cut into small pieces and grinded for short periods of time to get powder mixtures. Hundred grams of dried powder were mixed in $1000 \mathrm{ml}$ of $50 \%$ ethanol and $50 \%$ water. Every $10 \mathrm{gm}$ of powder mixed with $100 \mathrm{ml}$ of $50 \%$ ethanol in 250-ml conical flask. Mixtures were then irradiated with microwave for two minutes. The output power of the microwave oven is $300 \mathrm{~W}$. The suspension was irradiated for 25 seconds with power on to give the desired temperature of about $800 \mathrm{C}$ and then disconnect immediately and re-irradiate for 5 second with power on for heating and then for 10 minutes with power off for cooling. The process was repeated three times and the herb kept over night inside the refrigerator. The extract was finally filtered through gauze and evaporated under vacuum at 400C using a rotary evaporator. The extraction was dissolved in phosphate buffered saline (PBS, P4417), purchased from Sigma/USA (P4417 Sigma, USA).

Solar Irradiance: A Pyranometer instrument (LI-1000 LI-COR/USA) was used to measure the solar irradiance. The calibrated radiometer was mounted horizontally facing upwards. The range of measurements for the global solar irradiance during the experiments was $450-950 \mathrm{~W} / \mathrm{m}^{2}$ with an accuracy of about $3 \%$. Present experiments were conducted at UAE University (24011'50.92'’ $\mathrm{N}$ and 55041'03.04'’ $\mathrm{E})^{[17]}$.

Sample Preparation: Fresh human blood samples were donated by healthy volunteers. Red blood cells (RBCs) were isolated by centrifugation at $3000 \mathrm{~g}$ for 10 minutes at $4^{\circ} \mathrm{C}$. RBCs were mixed with diluted extract in addition to other ingredients as detailed later. Blood samples were mixed with phosphate buffered saline (PBS, pH= 7.4), and different dilutions of chicory's extract. All samples that contain extract are prepared in dark room. The kinetics of the fractional damage of the irradiated sample was followed spectrophotometrically by measuring the optical density as a function of time.

Samples with Additives: Collected RBCs were mixed with diluted extract plus some additives as described below: Three types of samples were investigated; samples contain RBCs plus herb with no additives (Control), samples contain RBCs plus herb plus $\mathrm{H}_{2} \mathrm{O}_{2}$ (29-32\%; Johnson Matthey Company, Germany), and samples with RBCs plus herb plus inulin. The inulin (A18425 from Johnson Matthey Company, Germany), was mixed in PBS by sonication. The concentration ranges used in this study were $0.95-0.75 \mathrm{mg} / \mathrm{ml}$ for chicory extracts, $0.3-0.7 \%$ for $\mathrm{H}_{2} \mathrm{O}_{2}$ and $1-2 \mathrm{mg} / \mathrm{ml}$ for inulin. Samples were incubated at $37^{0} \mathrm{C}$ for 10 minutes in a dark room, then centrifuged at $3000 \times \mathrm{g}$ for 10 minutes where the supernatant was removed. Prior to irradiation, $\mathrm{RBCs}$ were diluted with $\mathrm{PBS}$ to a final volume of $3 \mathrm{ml}$.

Spectrophotometry: Samples were incubated for 10 min at $37^{\circ} \mathrm{C}$ with or without light followed by the spectrophotometric measurements of the optical density at a fixed wavelength $(650 \mathrm{~nm})$. The optical densities were measured as a function of lysis time. The measurements were taken in a dark room and at room temperature.

\section{RESULTS}

Samples with $\mathrm{H}_{2} \mathrm{O}_{2}$ : Table 1 shows the effect of $\mathrm{H}_{2} \mathrm{O}_{2}$ on fractional hemolysis at two different temperatures. Samples were kept in total darkness during the preparation and exposure times. Control samples with $\mathrm{H}_{2} \mathrm{O}_{2}$ remained uneffected during the $150 \mathrm{~min}$ in total darkness at room temperatures (data not shown). The fractional hemolysis percentage dropped to $14.66 \%$ $3.68 \%$ during the $15 \mathrm{~min}$ at room temperature while the fractional hemolysis percentage dropped to $38.42 \%$ $76.12 \%$ during the same exposure time at $40^{\circ} \mathrm{C}$. At a fixed extract concentration $(0.95 \mathrm{mg} / \mathrm{ml})$ and with escalating $\quad \mathrm{H}_{2} \mathrm{O}_{2} \quad$ concentrations $\quad(0.3 \%-0.7 \%)$, temperature caused a reduction in the hemolysis rates by $90.46 \pm 0.39 \%$.

Table 1: Effect of light doses Fractional hemolysis of RBCs with different extracts and different $\mathrm{H}_{2} \mathrm{O}_{2}$ concentrations. Samples exposed for $15 \mathrm{~min}$ to two different temperatures at total darkness.

\begin{tabular}{lccl}
\hline $\begin{array}{l}\text { Extracts } \\
(\mathrm{mg} / \mathrm{ml})\end{array}$ & $\mathrm{H}_{2} \mathrm{O}_{2}(\%)$ & $\begin{array}{l}\text { Hemolysis }(\%) \\
\text { at } 24^{0} \mathrm{C}\end{array}$ & $\begin{array}{l}\text { Hemolysis }(\%) \\
\text { at } 24^{0} \mathrm{C}\end{array}$ \\
\hline 0.95 & 0.3 & 14.66 & 83.42 \\
0.90 & 0.4 & 11.76 & 83.40 \\
0.85 & 0.5 & 7.23 & 79.63 \\
0.80 & 0.6 & 5.01 & 79.20 \\
0.75 & 0.7 & 3.68 & 76.12 \\
\hline
\end{tabular}

Table 2 shows the samples mixed with RBCs, Fixed Extraction Concentration $(0.95 \mathrm{mg} / \mathrm{ml})$, and Different $\mathrm{H}_{2} \mathrm{O}_{2}$ concentrations. Group-I Exposed to $37^{0} \mathrm{C}$ for 10 min in total darkness followed by measurements of fractional hemolysis at $24^{0} \mathrm{C}$ while Group-II exposed to solar irradiation of $505.29 \pm 24.96 \mathrm{w} / \mathrm{m}^{2}$ for $10 \mathrm{~min}$. at $37^{0} \mathrm{C}$.

The time $\left(t_{50}\right)$ required to rupture $50 \%$ of the total RBCs, when $H=0.5 H_{0}$ were noticed in Group-II (Table $2)$. The time $\left(t_{50}\right)$ was not reachable in Group-I due to low acceleration of fractional hemolysis process. 
Am. J. Pharm. \& Toxicol., 2 (2): 75-79, 2007

Table 2: RBCs with fixed extraction concentration $(0.95 \mathrm{mg} / \mathrm{ml})$ and different $\mathrm{H}_{2} \mathrm{O}_{2}$ concentrations: Group-I temperature effect, samples exposed to $37^{\circ} \mathrm{C}$ for $10 \mathrm{~min}$. followed by measurements at $24^{\circ} \mathrm{C}$. Group-II light effect, samples exposed to solar irradiation for $10 \mathrm{~min}$. at $37^{\circ} \mathrm{C}$.

\begin{tabular}{llllll}
\hline Sample & $\mathrm{H}_{2} \mathrm{O}_{2}(\%)$ & $t_{50}(\mathrm{~min})$ & $a^{*}$ & $b^{\#}\left(\mathrm{~min}^{-1}\right)$ & $\mathrm{R}^{\$}$ \\
\hline Group I & 0.30 & N.A & $3.234 \pm 0.409$ & $0.050 \pm 0.008$ & 0.993 \\
Temp. & 0.40 & N.A & $3.244 \pm 0.782$ & $0.048 \pm 0.014$ & 0.975 \\
& 0.50 & N.A & $3.137 \pm 0.383$ & $0.055 \pm 0.007$ & 0.995 \\
& 0.60 & N.A & $3.393 \pm 0.367$ & $0.047 \pm 0.007$ & 0.995 \\
& 0.70 & N.A & $3.257 \pm 0.297$ & & 0.996 \\
\hline Group II & & & & $0.208 \pm 0.013$ & 0.998 \\
Light & 0.30 & 8.3 & $41.098 \pm 10.320$ & $0.149 \pm 0.010$ & 0.998 \\
& 0.40 & 13.3 & $21.612 \pm 4.632$ & $0.281 \pm 0.050$ & 0.999 \\
& 0.50 & 19.5 & $7.251 \pm 6.136$ & $0.196 \pm 0.046$ & 0.996 \\
& 0.60 & 22.7 & $9.664 \pm 7.841$ & $0.232 \pm 0.026$ & 0.999 \\
\hline
\end{tabular}

Results are expressed as means \pm SD

${ }^{*}$ Experimental values obtained from data curves at $H=0.5 H_{0}$

${ }^{\#}$ Theoretical values calculated from Eq. 1

${ }^{\$}$ Correlation coefficient

The fitted parameters $\boldsymbol{a}$ and $\boldsymbol{b}$ of Eq. 1 are concentration and temperature-dependent.

Figure 1 shows two groups, Group-I; where cells were exposed to temperature without light and Group-II; where cells were exposed only to light. A typical sigmoidal shape of photohemolysis curves are shown for Group-II were all the samples dropped more rapidly as compared to Group-I. Furthermore, cells with lower $\mathrm{H}_{2} \mathrm{O}_{2}$ concentration in Group-II were ruptured faster compared to those with higher $\mathrm{H}_{2} \mathrm{O}_{2}$ concentration as well as compared to the control line.

Samples with inulin: Figure 2 shows the curves with fixed extract concentration $0.95 \mathrm{mg} / \mathrm{ml}$ plus different concentrations of inulin. Samples were irradiated with direct sunlight at $505.29 \pm 24.96 \mathrm{w} / \mathrm{m}^{2}$ for $10 \mathrm{~min}$. at $37^{\circ} \mathrm{C}$. Samples with lower inulin concentration were faster in hemolysis process. The percentages of damaged cells were $80.15 \%, 61.25 \%$ and $47.55 \%$ for samples with inulin at $1.33 \mathrm{mg} / \mathrm{ml}$, $1.67 \mathrm{mg} / \mathrm{ml}$ and $2.00 \mathrm{mg} / \mathrm{ml}$ respectively. Samples with $0.95 \mathrm{mg} / \mathrm{ml}$ of herb and escalating concentrations of inulin $(1 \mathrm{mg} / \mathrm{ml}-2 \mathrm{mg} / \mathrm{ml})$ show no temperaturedependency at $40^{\circ} \mathrm{C}$ in the absence of sunlight (data not shown). conclusion

\section{DISCUSSION AND CONCLUSION}

A major objective of cancer treatment is the selective destruction of malignant cells without damaging normal tissues or affecting regular functions. Thus, the main objectives of the present study are to introduce a natural photosensitizer from herbal plants as

a potential PDT drug and to elucidate the effects of additive on their phototoxicity. This report is the first to assess the phototoxicity of the chicory extract. A comprehensive evaluation of the relationship between human phototoxicity and $\mathrm{RBC}$ photohemolysis has not been reported. In vitro studies of RBC photohemolysis

are based on Post-irradiation or "delayed photohemolysis" (DPH), in which a suspension of RBCs along with aqueous chicory's extract, $\mathrm{H}_{2} \mathrm{O}_{2}$ and inulin are exposed to direct dose of sunlight, followed by measurements of the hemolysis rate in the dark. Photohemolysis may be assayed by hemoglobin release and turbidity.

Some chemicals and drugs possess photosensitizing properties that lead to phototoxic responses in both human and animals. The adverse reactions induced by phototoxicity such as photohemolysis in vitro and photoirritation in vivo are mainly oxygen-dependent reactions ${ }^{[21]}$. Both in vivo and in vitro studies have related phototoxicity to the generation of reactive oxygen species (ROS) including $\mathrm{H}_{2} \mathrm{O}_{2}$ and the hydroxyl radicals. The accumulation of ROS results in oxidative stress which induces oxidative modifications of biomolecules of membranes such as lipids, DNA and proteins $^{[22,23]}$. However photosensitivity reactions can have beneficial effects as in tumor PDT. Treatments for malignant tumors employ the interaction of a photosensitizer with appropriate wavelength in the presence of molecular oxygen and light ${ }^{[24]}$. Photosensitization implies that, in the absence of an absorbing pigment, an organism does not react to light of certain wavelengths. The spectrum of the dissolved extracted materials shows a strong absorption bands at ultraviolet and visible wavelengths regions (data not shown). The extract of flowers and aerial parts of the chicory (Cichorium Pumilum Jacq) is viscous, pasty and water soluble. Extract of plant pigment hypericin 
(HY) has been shown to mediate the release of hemoglobin under the influence of light ${ }^{[25]}$.

The effect of $\mathrm{H}_{2} \mathrm{O}_{2}$ on phototoxicity reported in this study showed a rapid reduction in the fractional hemolysis percentage at higher concentrations which reflects the inhibitory effect of $\mathrm{H}_{2} \mathrm{O}_{2}$ (Table 2: Group-II and Fig. 1). This rapid reduction could be partially explained by means of photobleaching of the extracts due to some possible oxidative reaction ${ }^{[26]}$.

The values of the fitted parameters of Eq.1; ratio $\boldsymbol{a}$ and the rate $\boldsymbol{b}$ are higher values under the influence of light as compared to temperature (Table 2). The ratio $\boldsymbol{a}$ was almost unaffected in Group-I while a rapid reduction in Group-II was noticed. These results are consistent with my previous finding when $1 \mathrm{mM}$ of $\mathrm{H}_{2} \mathrm{O}_{2}$ was added to RBCs plus protoporphyrin IX irradiated with black light ${ }^{[19]}$. The fitted experimental data points to Eq. 1 are in good agreement with the theoretical experimental lysis curves (Fig. 1). The rapid damage to the RBCs in Group-II could be explained by the cooperative photochemical and thermal processes, while the very slow process in Group-I could be explained by the thermal effect only ${ }^{[17-19,25]}$.

The results of inulin show that the cellular degradation decreases as the inulin concentration increases. This could be attributed to the increase of relative number of free radicals that attacking the dye molecule ${ }^{[27]}$. Therefore, the addition of inulin to the herbal extract could slow down the photohemolysis process at specific concentration range $(1.0 \mathrm{mg} / \mathrm{ml}$ $2.0 \mathrm{mg} / \mathrm{ml}$ ). The present results are in agreement with earlier report where $2 \%$ of inulin was added to the blood and higher inhibition values were obtained. It is, therefore, worthwhile to supplement blood with inulin to avoid undesirable changes during chill storage or/and to prevent the effects of a cold-chain breakdown ${ }^{[28]}$. Some other studies reported that inulin (chicory fiber) could increase the rate of apoptosis and thereby helps preventing cancer and inhibiting the colonic preneoplastic lesions ${ }^{[29]}$. In addition, cichoriin and lactucin, extracted from the chicory flowers and roots respectively, have been reported to be sensitive to light ${ }^{[2,1,10]}$. Therefore, cichoriin and Lactucin could be the main photosensitizers that confer chicory's phototoxicity.

In conclusion, low sunlight intensity (ultraviolet and visible light) could cause a very high mortality rate in the present of chicory extracts and play a major role of phototoxicity. Chicory's extract was found to be bolthy. light and temperature dependent. Samples with inulin and $\mathrm{H}_{2} \mathrm{O}_{2}$ are affected by light, while the temperature effect was restricted to samples with $\mathrm{H}_{2} \mathrm{O}_{2}$ only. Finally, the results reported in this study provide more information about membrane photosensitization that could lead to developing a new PTD agent with minimal side effects. The novel aspects of this work are the qualitative and quantitative modeling of photohemolysis kinetics where the experimental data and theoretical fitting are in very good agreement.

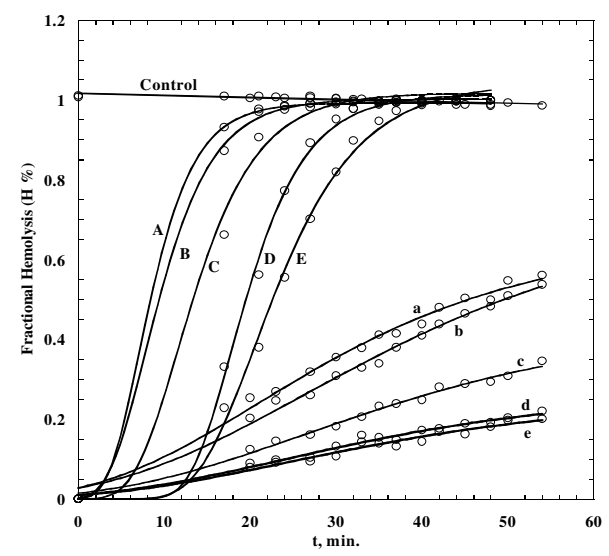

Fig. 1: Group-I, Different Concentration of $\mathrm{H}_{2} \mathrm{O}_{2}$ exposed to $25^{\circ} \mathrm{C}$ without sun light for $10 \mathrm{~min}$. at $25^{\circ} \mathrm{C}(\mathrm{a} 0.3 \%$, b $0.4 \%$, c $0.5 \%, \mathrm{~d} 0.6 \%$ and e $0.7 \%$ ) and Group-II, Different Concentration of $\mathrm{H}_{2} \mathrm{O}_{2}$ irradiated with sunlight at $25^{\circ} \mathrm{C}$ and $505.29 \pm 24.96 \mathrm{w} / \mathrm{m}^{2}$ radiance (A $0.3 \%, \mathrm{~B} 0.4 \%, \mathrm{C} 0.5 \%$, D $0.6 \%$, and $\mathrm{E} 0.7 \%$ ).

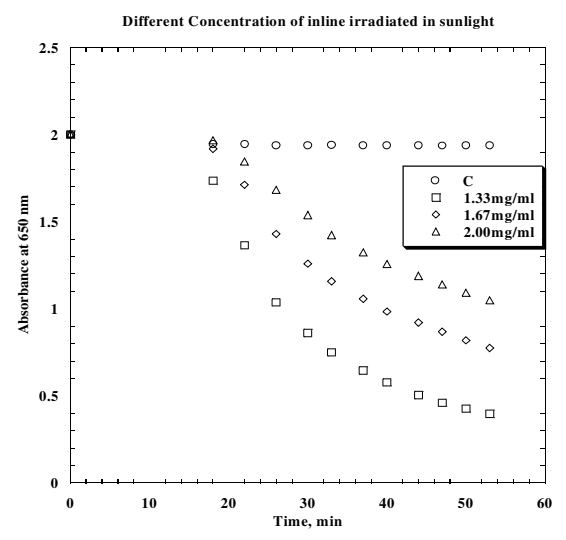

Fig. 2: Different concentration of inulin irradiated with sunlight at $37^{\circ} \mathrm{C}$ and $505.29 \pm 24.96 \mathrm{w} / \mathrm{m}^{2}$ radiance.

\section{ACKNOWLEDGEMENTS}

This work was funded by the Scientific Research Council of United Arab Emirates, grant \# 0802-2-11/06 and partially by Higher Council for Science and Technology/Jordan, grant \# 62/2000. 


\section{REFERENCES}

1. Biscoff, T., C. Kelley, Y. Karchesy, M. Laurantos, P. Nguyen-Dinh, A. Arefi, 2004. Antimalarial activity of Lactucin and Lactucopicrin: Sesquiterpene Lactones Isolated from Cichorium Intybus L. J. Ethnopharmacology 95: 455-457.

2. Petrovic, J., Stanojkovic, A., Comic, Lj., Curcic, S. 2004. Antibacterial activity of Cichorium Intybus. Fitoterapia 75: 737-739.

3. Hartwell, J.L. 1967-1971. Plants used against cancer: A survey. Lloydia 30-34

4. Amin, A., Mousa, M. 2007. Merits of anti-cancer plants from the Arabian Gulf region. Cancer Therapy 5, 55-66.

5. Hazra, B. Sarkar, R. Bhattacharyya, S. Roy, P. 2002. Tumour inhibitory activity of chicory root extract against Ehrlich ascites arcinoma in mice. Fitoterapia, 73: 730-733.

6. Pushparaj, P. Low,H. Manikandan, J. Tan,B. Tan,C. Anti-Diabetic effects of Cichorium intybus in streptozotocin-induced diabetic rats. Journal of Ethnopharmacology: In Press.

7. Bahar, A. Tawfeq, A. Al-Howiring, A. and Siddiqui, A. 2003. Antihepatotoxic activity of seeds of Cichorium intybus. Journal of Ethnopharmacology. 87: 237-240.

8. Cheryl, L. Turner, N. Brauer, G. Lourenco, G and Georges, K. 2006. Ethnoveterinary medicines used for horses in Trinidad and in British Columbia, Canada. Journal of Ethnobiology and Ethnomedicine. 2:31.

9. Harborne, J. 1960. The coumarins of Solanum pinnatisectum. Plant Polyphenols.74: 270-273.

10. Frey, U., Claude, J., Crelier, S., Juillert, M. 2002. UV degradation of sesquiterpene lactones in Chicory extract kinetics and identification of reaction products by HPLC-MS. Chmia 56: 292293.

11. Barry, T.N., Hoskin, S.O., Wilson, P.R., 2002. Novel forages for growth and health in farmed deer. NZ. Vet. J. 50: 244-251.

12. Marley, C.L., Cook, R., Keatinge, R., Barrett, J., Lampkin, N.H., 2003. The effect of birdsfoot trefoil (Lotus corniculatus) and chicory (Cichorium Pumilum) on parasite intensities and perfor-mance of lambs naturally-infected with helminth parasites. Veterinary Parasitology 112, 147-155.

13. Marley, C. R. Cook, J. Barrett, R. Keatinge, N.H. Lampkin. (2006) The effects of fbirdsfoot trefoil (Lotus corniculatus) and chicory (Cichorium Pumilum) when compared with perennial ryegrass (Lolium perenne) on ovine gastrointestinal parasite development, survival and migration. Veterinary Parasitology 138: 280-290.

14. Schreurs, N.M., Molan, A.L., Lopez-Villalobos, N., Barry, T.N., McNabb, W.C., 2002. Effects of grazing undrenched weaner deer on chicory or perennial ryegrass/white clover pasture on the viability of gastrointestinal nematodes and lungworms. Vet. Rec. 151, 348.
15. Boeuf, G., B. Legrand, and S. Rambour, 1999. Influence of light conditions on development, apoplastic peroxidase activities and peroxidase isoenzymes in chicory root explants. Physiol. Plant., 106: 331-336.

16. Wight, W. A., Niekerk, J. V. 1983. Determination of reducing sugars, sucrose and insulin. Journal of Agriculture and Food Chemistry 31: 282-285.

17. Al-Akhras, M. Amr Amin, Karima Mohammad, Fedae Al-Haddad, Allaaeldin Hamza. 2007. In vitro studies on the effect of phototoxicity of a new photosensitizer extracted from flowers and aerial parts of Cichorium Pumilum. A. J. Phramcol. Toxicol. 2: 39-45.

18. Al-Akhras M. 2006. A New Application of Gompertz Function in Photohemolysis: The Effect of Temperature on Red Blood Cell Hemolysis Photosensitized by Protoporphyrin IX. Medical \& Biological Eng \& Computing., 44: 703-710.

19. Al-Akhras M. 2006. Effect of Additives and Photosensitive Drugs on Osmotic Fragility. Int. J. Sci. Res. 16, pp.363-369.

20. Pan, X., G. Niu, and H. Liu, 2003. Microwaveassisted extraction of tea polyphenols and tea caffeine from green tea leaves. Chem. Eng. Process. 42: 129-133.

21. Nam, C. An, S. Lee, E. Moon, S. Kang, J. and Chang, I. 2004. An In Vitro Phototoxicity Assay Battery (Photohaemolysis and 3T3 NRU PT test) to Assess Phototoxic Potential of Fragrances. Skin and phototoxicity. 32: 693-697.

22. Djordjevic VB, 2004. Free radicals in cell biology. Int Rev.Cytology 237:57-89.

23. Sorg O, 2004. Oxidative stress: a theoretical model or a biological reality. C R Biologies 327:649-662.

24. Henderson, BW., Dougherty, T. 1992. How does photodynamic therapy work? Photochem Photobiol, 55: 145-157.

25. Al-Akhras, M., Grossweiner, L. 1996. Sensitization of photohemolysis by hypericin and Photofrin ${ }^{\circledR}$. J. Photochem. Photobiol. B Biol., 34: 169-175.

26. Qamar, M, Saquib, M. Muneer, M. 2005. Photocatalytic degradation of two selected dye derivatives, chromotrope $2 \mathrm{~B}$ and amido black 10B, in aqueous suspensions of titanium dioxide. Dye and Pigments 65: 1-9.

27. Senthilkumaar, S. Porkodi, K. Vidyalakshmi,R. 2005. Photodegradation of a textile dye catalyzed by sol-gel derived nanocrystalline $\mathrm{TiO}_{2}$ via ultrasonic irradiation. J. Photochem. Photobiol. A: Chemistry. 170: 225-232.

28. Daila, E. Saguer, E. Toldra, M. Carretero, C. Pares, D. 2006. Preservation of porcine blood quality by means of lactic acid bacteria. Meat Science. 73: 386-393.

29. Bengmark, S. 2000. Bacteria for optimal health. Nutrition. 16: 611-615. 